\title{
Eğitim Bilişim Ağında Yer Alan Türkçe Dersi Videoları Üzerine Bir İnceleme
}

\begin{abstract}
Murat ATEŞ*
Arif ÇERÇi் ${ }^{* *}$

Serdar DERMAN ${ }^{* * *}$

Öz

Dil öğretiminde temel amaç, dil becerilerinin geliştirilmesi ve öğretimi yapılan dilin kurallarının sezdirilmesidir. Bu doğrultuda öğretim surecine dahil olan bütün etmenler öğretimin verimliliğini artırmak üzere düzenlenir. Günümüzde teknolojik gelişmelere bağlı olarak uzaktan eğitim uygulaması yaygınlaşmıştır. Türkçe öğretiminde de teknolojinin getirdiği yenilik ve kolaylıklardan faydalanmak verimliliği artıracaktır. Bu düşüncelere bağlı olarak son dönemlerde Türkçe öğretimini uzaktan eğitim uygulamalarına uyumlu hâle getirme çalışmaları hız kazanmıştır. Eğitimde fırsatları artırma ve teknolojiyi iyileştirme hareketinin (FATİH Projesi) önemli birleşenlerinden biri de eğitsel e-içeriğin sağlanması ve yönetilmesidir. Bu amaçla Eğitim Bilişim A $\breve{g}$ (EBA) oluşturulmuş ve elektronik içerikler bu ağ üzerinden hizmete sunulmuştur. EBA'daki e-içeriklerin önemli bir bölümünü ders videoları oluşturmaktadır. Araştırmada Türkçe dersi videolarının sistematik bir anlayışla ele alınması amaçlanmış; böylece bu videoların -“FATïH Projesi” kapsamında- amaca ne ölçüde katkı sağladığı incelenmiştir. EBA'da Türkçe dersi videolarını çeşitli değişkenler bakımından sistematik bir şekilde incelemeye yönelik betimsel bir araştırmadır. Çalışmada nitel araştırma yöntemlerinden doküman inceleme yöntemi kullanılmıştır. Bu araştırmada analiz edilen Türkçe ders videoları 16 Nisan 2015 tarihinde EBA'da erişilebilen 5, 6, 7 ve 8. sınıf öğrenciler için hazırlanmış Türkçe ders sunumlarını kapsamaktadır. 125 ders videosu araştırmacıların her biri tarafından üçer defa izlenmiş önceden belirlenmiş yedi (7) soru açısından incelemeye tabi tutulmuştur. Ulaşılan sonuçlar her alt amaca uygun olarak tablolar hâlinde sonuçlandırılmıştır
\end{abstract}

Anahtar Kelimeler: Eğitim Bilişim Ağı, Türkçe dersi videoları, doküman analizi.

\section{Content Analysis of Turkish Course Videos in Educational}

\section{Informatics Network}

\begin{abstract}
One of the important components of enhancing opportunities and improving technology movement (FATIH) project in education is to provide and manage educational e-content. For this purpose, Educational Informatics Network (EBA) was created and electronic contents were put into service via this network. A vast majority of the contents in EBA were composed of course videos. In this study, it was aimed to examine Turkish courses in a systematic way, thus a content analysis method was used to investigate to what extent these videos contribute to the objectives of FATIH project. The present study is a descriptive one and it systematically examines Turkish course vi-
\end{abstract}

\footnotetext{
*Yrd. Doç. Dr., Necmettin Erbakan Üniversitesi, Türkçe Eğitimi Bölümü, mates@konya.edu.tr

** Yrd. Doç. Dr., Gaziantep Üniversitesi, Türkçe Eğitimi Bölümü, arifcerci@gmail.com

${ }^{* * *}$ Yrd. Doç. Dr., Gaziantep Üniversitesi, Türkçe Eğitimi Bölümü, serdarderman@gmail.com
} 
deos on EBA in terms of different variables. This study applied document analysis technique with a qualitative approach. Turkish course videos analyzed in the current study involved the course presentations prepared for 5, 6, 7, and 8th grade students which could be available from http://www.eba.gov.tr/video/ortaokul-5-sinif-turkce, http://www.eba.gov.tr/video/ortaokul-6-sinifturkce, http://www.eba.gov.tr/video/ortaokul-7-sinif-turkce, http://www.eba.gov.tr/ video/ortaokul-8-sinif-turkce. 125 course videos were watched three times by researchers and examined according to the predetermined seven themes and subcategories of these themes. Results were given in tables convenient to each sub-goal.

Keywords: Educational Informatics, Turkish course videos, content analysis.

\section{Gíriş}

Dil öğretiminin temel amacl, öğrencilerin dilin farklı bağlamlarda aldığı görünümleri kavramaları, dil aracılığıyla kendilerini ifade edebilmeleri, değişik bilgi kaynaklarına ulaşarak duygu, düşünce ve hayal dünyalarını zenginleştirmeleridir (MEB, 2006: 2).

2006 Türkçe Öğretim Programında okuma, dinleme/izleme, konuşma ve yazma öğrenme alanları ile dilbilgisi konuları yer almaktadır. Programın hedefi kazanımların etkinlikler yoluyla, öğrencinin birikim ve deneyimlerinden hareketle verilmesidir. Programdaki temel yaklaşım ele alındığında, öğretmen bir rehberdir. $\mathrm{Bu}$ rehber, öğrencinin gelişim düzeyini dikkate alarak öğrencinin öğrendiklerini yapılandırmasına yardımcı olur. Öğrenciyi merkeze alan bir yaklaşımla hazırlanan programda, bütün kazanım ve etkinliklerin odak noktası doğal olarak öğrencidir.

Programdaki temel yaklaşımı belirleyen ve şekillendiren, yapılandırmacı öğrenme yaklaşımıdır. Bu yaklaşıma göre, öğrenci yeni bir bilgi ile karşılaştı̆̆ zaman, dünyayı tanımak ve açıklamak için önceden oluşturduğu kurallarından yararlanır veya algıladığ 1 yeni bilgiyi açıklamak için yeni kurallar oluşturur (Brooks ve Brooks, 1999: 9).

Aynı durumu Sever (2004: 31) de dile getirmektedir; yeni bir öğrenme, önceki öğrenmelere dayanır ve kendisinden sonraki öğrenmelerin de hazırlayıcısıdır. Yürürlükteki Türkçe Programında da öğrenmelerin önceki öğrenmeler üzerine yapılandırıldığı anlayışına dayanan "yapılandırmacı" eğitim anlayışı temel alınmıştır. Bu eğitim anlayışıyla ilgili değerlendirmeler temelde aynı noktaları vurgular niteliktedir.
Akyol görüşünü "yapılandırmacı yaklaşımda bir rehber, yardımcı ya da dost olan öğretmen, öğrencilerin cevabindan hareketle öğretim stratejilerini ayarlamalı ve öğrenciler arasında diyaloglar kurarak, öğrencilere farkh sorular sorarak, öğrencilerin dikkatini çekerek ve öğrencilerin farkl düşünmelerini sağlayarak onları analiz etmeye, yorumlamaya ve tahmin etmeye teşvik etmelidir" (2007: 244) şeklinde dile getirir.

Söz konusu eğitim yaklaşımının bireyin eğitimi açısından faydasının altını çizmek gerekir. "Yapılandırmacı öğrenme yaklaşımında, öğrenci kendini özgürce ifade edebileceği bir sınıf ortamında, günlük hayat problemlerinin karmaşıklı̆̆ını çözerek yaşam boyu kullanacağı bilgileri oluşturur" (Karadağ ve Korkmaz, 2007: 40).

Güneş, yapılandırmacı yaklaşımın ders içindeki süreçlerini şu şekilde ortaya koyar: "Öğrenme-öğretme sürecini de etkilemektedir. Yapılandırmacı yaklaşıma göre Türkçe öğretiminin öğrenmeöğretme süreci beş aşamada ele alınmaktadır. Bunlar: Hazırlık, anlama, metin aracılığı ile öğrenme, kendini ifade etme ve ölçme ve değerlendirme aşamalarıdır. Öğrenciler her aşamada çeşitli etkinlikler yoluyla aktif duruma getirilmektedir" (2009: 18).

Ders anlatımıyla ilgili sağlıklı analizler yapabilmek için dil öğretimi açısından doğru eğitim anlayışını ortaya koymak gerekir. Bu sebeple Eğitim Bilişim Ağı (EBA) Türkçe ders videolarını değerlendirirken eğitim yaklaşımı, üzerinde durulması gereken önemli bir nokta olarak görülmüştür. Diğer taraftan Türkçe öğretiminin ilkeleri göz önüne alınmadan yapılacak değerlendirmeler de yine sağlıksız olacaktır.

Özdemir, “Anadili öğretiminde çocuğun dilsel evreni çıkış noktası olacaktır. Çocuğun dilsel evreniyse çevresiyle, ilgi ve gereksinimleriyle 
sınırlıdır. Eğitimin değişik aşamalarında bu sınır aşamalı bir biçimde geliştirilecektir" (1983: 26) der ve Türkçe öğretiminin genel ilkelerini şu şekilde sıralar:

- Anadili etkinlikleri belli bir ilişki ağı içinde bir bütün oluşturur: konuşma dinlemeyi, dinleme anlamayı, anlama söze ve yazıya dönüştürmeyi gerektirir. Etkinlikler arasındaki ilişki ağı, derslerin akışını ve değişkenliğini oluşturmalıdır.

- Anadili dersi bir bilgi dersi değil, bir beceri ve alışkanlık dersidir. Alışkanlığın oluşması, becerilerin kazanılması ise yapmayı ve uygulatmayı gerektirir.

- Anadili dersi, bir alışkanlık ve beceri dersi olduğu kadar insan kişiliğini kurma, geliştirme dersidir. Bu derste inceletilecek metinler, bunlar üzerinde yaptırılacak çalışmalar, kişiliğin oluşumunda önemli bir yeri olan ulusal bilinci ve coşkuyu kazanma, olayları neden sonuç ilişkisi içinde ele alarak yargılama gücünü geliştirme, güzel metinler aracılığıyla dil beğenisini yerleştirme, yazma ve okuma etkinliğiyle imgelem gücünü besleme, güzel ve etkili anlatma amacına yönelik olmalıdır.

- Anadili dersi hem bir amaç hem de bir araç derstir. Bu bağlamda her ders bir ölçüde anadili dersi, her öğretmen de anadili öğretmenidir. Biçimsel bir benzetme değildir bu. Anadili öğretiminde sürdürülen ve alışkanlığa dönüştürülmek istenen davranışlar tüm öteki dersleri de kuşatır. Özetlemeli bir tutumla sıraladığımız bu ilkeler, anadili öğretiminin yöntemini de ortaya koymaktadır"

Kavcar ve arkadaşları (2005: 9) Türkçe dersinin öğrencilere kazandıracağı davranış ve yeterlilikleri "anlama gücü, anlatma becerisi, dinleme ve okuma alışkanlığı, dilbilgisi ve yazım kurallarının kavranılması, dil sevgi ve bilincinin edinilmesi" olarak belirtmiş ve öğretim sırasında göz önünde bulundurulması gereken ilkeleri şu şekilde belirlemişlerdir:

Dil doğal bir ortam içinde öğretilmelidir.

Öğretimde çocuğun kendi dilinden hareket edilmelidir.
Türkçe öğretiminde bütün derslerden yararlanilmalıdır.

Değişik dil çalışmaları arasında sıkı bir ilişki kurulmalıdır.

Çeşitli ders araç ve gereçlerinden yararlanılmalidir.

Türkçe öğretiminin bu ilkelerine uygun olarak modern eğitim anlayışlarına, genel öğretim yöntemlerine ve özel öğretim tekniklerine göre yapılan bir dil öğretiminde başarı yüksek olacaktır. Başarıyı yükseltecek her türlü öğretim yolu denenmelidir. Değişik ders araç ve gereçlerinden yararlanma Türkçe öğretimi açısından son derece önemlidir. Sadece ders kitaplarına bağlı kalmak öğretim sürecinin amaciyla bağdaşmadığı gibi süreci tekdüze hâle getirir. Türkçe öğretiminde ders kitapları amaç değil, diğer materyaller gibi birer araçtır. Dersleri ders kitabına bağlı kalarak işlemek, ders kitabını amaç hâline getirir. Böyle bir durumda ise öğrenci diğer öğrenme araçlarını gereksiz görür. Öğrenme materyallerinin zengin tutulması Türkçe Dersi Öğretim Programı (MEB, 2005)'nda da yer almaktadır.

Hızla değişen ve gelişen dünyada eğitim ve öğretim de çağın gereklerine uygun olmalıdır. Aksi takdirde belirlenen millî hedeflerden biri olan "Bilim ve teknoloji üretiminde odak noktası hâline gelmiş, bilgi ve teknolojiyi etkin bir araç olarak kullanan, bilgiye dayalı karar alma süreçleriyle daha fazla değer üreten, küresel rekabette başarılı ve refah düzeyi yüksek bir ülke olmak" (DPT, 2006) idealinden uzaklaşılır.

Belirtilen hedeflere ulaşma yolunda, Millî Eğitim Bakanlığı ile Ulaştırma Denizcilik ve Haberleşme Bakanlığ de, "FATIH' olarak kodlanan "Firsatları Artırma Teknolojiyi İyileştirme Hareketi " projesini geliştirmiş ve bu proje hayata geçirilmeye başlanmıştır. Eğitimde FATİH projesi beş ana bileşenden oluşmaktadır (MEB, 2015).

1. Donanım ve Yazılım Altyapısının SağlanmaS1

2. Eğitsel e-içeriğin Sağlanması ve Yönetilmesi 
3. Öğretim Programlarında Etkin Bilgisayar Teknolojileri Kullanımı

\section{4. Öğretmenlerin Hizmetiçi Eğitimi}

5. Bilinçli, Güvenli, Yönetilebilir ve Ölçülebilir Bilgisayar Teknolojileri Kullanımının Sağlanmas1

$\mathrm{Bu}$ projenin önemli unsurlarından biri de, FATïH Projesi'nin ikinci ana bileşenini oluşturan “EBA" olarak kısaltılan Eğitim Bilişim Ağı'dır. $\mathrm{Bu}$ sanal ortamın özellikleri ve hedefleri şunlardır: "Eğitim-öğretim sürecinde bilişim teknolojisi donanımlarını kullanarak etkin materyaller kullanılması amacıyla Yenilik ve Eğitim Teknolojileri Genel Müdürlüğü tarafından tasarlanan EBA sınıf seviyelerine uygun, güvenilir ve incelemeden geçmiş doğru e-içeriklerin bulunabileceği sosyal bir platformdur. Öğretmen ve öğrenciler başta olmak üzere eğitimin bütün paydaşları için tasarlanan EBA;

Farklı, zengin ve eğitici içerikler sunmak,

Bilişim kültürünü yaygınlaştırarak eğitimde kullanılmasını sağlamak,

İçerikle ilgili ihtiyaçlarınıza cevap vermek,

Sosyal ağ yapısıyla bilgi alışverişinde bulunmak,

Zengin ve gittikçe büyüyen arşiviyle derslere katkı sağlamak,

Bilgiyi öğrenirken aynı zamanda yeniden yapılandırabilmek ve bilgiden bilgi üretmek,

Farklı öğrenme stillerine (sözel, görsel, sayısal, sosyal, bireysel, işitsel öğrenme) sahip öğrencileri de kapsamak,

Bütün öğretmenleri ortak bir paydada buluşturarak eğitime el birliğiyle yön vermelerine ön ayak olmak,

Teknolojiyi bir amaç olarak değil bir araç olarak kullanmak amaciyla tasarlanan sosyal bir eğitim platformudur" (MEB, 2015). Teknolojinin her alanda kullanıldığı günümüz sosyal hayatı göz önüne alındığında bu platformun eğitim-öğretim alanında önemli bir işlev üstlendiği muhakkaktır ama buradaki eğitimöğretim etkinliklerinin ve materyallerinin farklı bakış açılarıyla incelenmesi bu platformun daha işlevsel ve faydalı hâle getirilebilmesine katkı sağlayacaktır.

\subsection{Araştırmanın Amacı}

Çalışmanın amacı, EBA'da yer alan Türkçe dersi video içeriklerini öğrenme alanları, süreleri, etkileşim özellikleri, öğretme/öğrenme stratejileri gibi çeşitli değişkenler açısından sistematik olarak incelemektir. Böylece Türkçe derslerinde kullanılan bu elektronik içeriklerin Türkçe öğretimi bakımından özelliklerini ortaya koyarak, amacina uygun kullanılmasina katkı sunmak amaçlanmaktadır.

Çalışmada bu amaca bağlı olarak aşağıdaki sorulara cevap aranmıştır:

1. EBA'da yer alan Türkçe dersi videolarının sınıflara göre dağılımı nasıldır?

2. EBA'da yer alan Türkçe dersi videolarının ders süreleri ne kadardır?

3. EBA'da yer alan Türkçe dersi videolarının izlenme sayılarına göre dağılımı nasıldır?

4. EBA'da yer alan Türkçe dersi videolarının, kazanım dağılımı bakımından, dersin anlatıldığ1 sınıf düzeyine uygunluğu nedir?

5. EBA'da yer alan Türkçe dersi videolarında ele alınan konular Türkçe Öğretim Programında yer alan hangi kazanımlarla ilişkilidir?

6 EBA'da yer alan videolarda ders işleme süreci aşamalarına yer verilmiş midir?.

7. EBA'da yer alan videolarda hangi öğretim stratejileri kullanılmıştır?

\section{YÖNTEM}

Bu çalışma, Eğitim Bilişim Ağ̀ (EBA)'nda yer alan Türkçe dersi videolarını çeşitli değişkenler bakımından sistematik bir şekilde incelemeye yönelik betimsel bir araştırmadır. Çalışmada nitel araştırma yöntemlerinden doküman incelemesi yöntemi kullanılmıştır. Doküman incelemesi, araştırılması hedeflenen olgu ve olgular hakkında bilgi içeren, yazılı, görsel materyallerin analizini kapsar. Dokümanlar nitel araştırmalarda etkili bir şekilde kullanılması gereken 
bilgi kaynaklarıdır (Yıldırım ve Şimşek, 2008: 187-188).

\subsection{Verilerin Toplanması}

Bu araştırmada analiz edilen Türkçe ders videolar1 16 Nisan 2015 tarihinde http://www.eba.gov.tr/video/ortaokul-6-sinifturkce, http://www.eba.gov.tr/video/ortaokul7-sinif-turkce,

http://www.eba.gov.tr/video/ortaokul-8-sinifturkce, internet adreslerinde erişilebilen 5. Sinıf (n10) 6. $\sin i f(n=4), 7$. sinif $(n=37)$ ve 8 . sinif ( $\mathrm{n}=76$ ) Türkçe dersi videolarıla sınırlıdır. 5, 6, 7 ve 8 . sinıf düzeyinde bütün Türkçe ders videoları izlenmiş; fakat 8. sınıf videoları arasında yer alan "Türkçe Dersi Çalışma Teknikleri” adlı ve konulu bir video ile 5. sinıf videoları arasında "Öğretmenim" başlıklı bir video Türkçe dersi sunusu niteliği taşımadığı için çalışmaya dâhil edilmemiştir. Böylece veriler 125 Türkçe dersi videosundan derlenmiştir.

\subsection{Verilerin Analizi}

Çalışmanın verileri betimsel olarak analiz edilmiştir. Betimsel analizde elde edilen veriler, daha önceden belirlenen temalara göre özetlenir ve yorumlanır. Veriler araştırma sorularının ortaya koyduğu temalara göre düzenlenebileceği gibi, süreçte kullanılan soru ya da boyutlara göre de sunulabilir. (Yıldırım ve Şimşek, 2013).

İncelenen videolarla ilgili analiz için önce bir çerçeve oluşturulmuştur. Çerçeve oluşturma sürecinde ise alanda yapılan araştırma sonuçlarindan (Saban, 2009; Kayısı ve Aydın, 2014; Tarhan, 2010; Yurt ve Aslan, 2014) yararlanılmıştır. Yapılan incelemeler sonucunda analizde kullanılacak 7 soru belirlenmiştir. Hazırlanan sorular Türkçe Eğitimi alanında uzman kişilerin görüşlerine sunulmuştur. Uzmanlardan gelen görüşlere bağlı olarak sorular yeniden düzenlenmiş ve uzmanlara yeniden gönderil- miştir. Gelen dönütler, uzmanların görüş birliği içinde oldukları yönündedir.

\subsection{Verilerin Kodlanması ve Çözümlenmesi}

İçerik analizine tabi tutulan 125 video birçok defa izlenmiş ve içerik analizi yönergesinde yer alan yedi (7) soru/temanın her biri için alt temalar belirlenmiştir. Örneğin Türkçe ders videolarında kullamılan öğretim stratejilerinin dağılımı nasıldır? Sorusuyla analiz edilen tema için 4 adet alt tema "sunuş yoluyla öğretim", "buluş yoluyla öğretim", araştırma- inceleme yoluyla öğretim", "tam öğrenme modeli" belirlenmiştir. Sonrasında 125 video yeniden izlenerek her "alt tema" için tek tek kodlanmıştır.

Araştırmadaki kodlama on beş gün arayla iki defa yapılmıştır. İki kodlama karşılaştırılmış ve güvenirlik (güvenirlik = görüş birliği $/$ görüş birliği + görüş ayrıllğ 1 x 100) (Miles ve Huberman, 1994) formulü ile hesaplanmış, iki kodlama arasındaki uyum \%100 olarak bulunmuştur. Kodlanan verilerin çözümlenmesi için SPSS paket programı kullanılmıştır. Önce bütün temalar ve alt temalar SPSS paket programina aktarılmıştır. Sonrasında ilgili temanın/alt temanın videolarda var olup olmadığına ("var" veya "yok" şeklinde) bakılmış ve bu temaların kaç kez tekrarlandığ frekans (f) ve yüzde (\%) olarak hesaplanmıştır. Araştırmadan elde edilen verilerden, sadece tek veri elde edilen temalara dönük tablolar hazırlanmamıştır. Bunun yerine bu bulgular paragraflar hâlinde yorumlanmıştır.

\section{BULGULAR}

Bu bölümde araştırma sürecinde yapılan analizler sonucu elde edilen bulgular tablolar hâlinde gösterilmiştir, her bir alt amaca yönelik soruya ait bulgular tabloların altında yorumlanmıştır.

3.1 EBA'da yer alan Türkçe dersi videolarının sınıflara göre dağılımı nasıldır? 
Tablo 1. Türkçe Dersi Videolarının Sınıflara Göre Dağılımı

\begin{tabular}{lll}
\hline Sinıf & $f$ & $\%$ \\
\hline 5. Sinıf Videoları & 9 & 7,2 \\
6. Sinıf videoları & 4 & 3,2 \\
7. sinıf videoları & 37 & 29,6 \\
8. Sinıf videoları & 75 & 60 \\
Toplam & 125 & 100 \\
\hline
\end{tabular}

Tablo 1, EBA'da yer alan Türkçe dersi videolarının sınıflara göre dağılımını göstermektedir. Buna göre 125 (yüz yirmi beş) Türkçe dersi videosundan dokuzu $(\% 7,2) 5$. sinif; dördü $(\% 3,2)$ 6. sinıf; otuz yedisi $(\% 29,6) 7$. sinif; yetmiş beşi (\%60) ise 8 . sınıflar için hazırlanmıştır.
Türkçe dersi videolarının yarıdan çoğu 8. sınıflara yöneliktir. Ortaöğretime geçiş sınavlarının 8. sınıfta yapılıyor olması bu sınıf düzeyindeki içeriklerin sayısının fazlalığını açıklayabilir.

3.2 EBA'da yer alan Türkçe dersi videolarının ders süreleri ne kadardır?

Tablo 2. Türkçe Dersi Videolarının Sürelerine Göre Dağılımı

\begin{tabular}{lll}
\hline Süre & $f$ & $\%$ \\
\hline 1-5 dakika & 51 & 40,8 \\
6-10 dakika & 54 & 43,2 \\
11-15 dakika & 14 & 11,2 \\
16-20 dakika & 3 & 2,4 \\
21 dakika ve üzeri & 3 & 2,4 \\
\hline
\end{tabular}

Tablo 2, EBA'da yer alan Türkçe dersi videolarının sürelerini göstermektedir. Buna göre EBA'da yer alan 125 Türkçe dersi videosundan 51'i $(\% 40,8)$ bir dakika ile beş dakika arasında; $54^{\prime}$ ü $(\% 43,2)$ altı dakika ile on dakika arasında; $14^{\prime}$ ü $(\% 11,2)$ on bir dakika ile on beş dakika arasında; 3 'er tanesi $(\% 2,4)$ ise on altı ile yirmi dakika arasında ve yirmi bir dakika üzerindedir. Videolarda amaçlanan kazanımlar ve ders süreçleri dikkate alındığında Türkçe dersi videolarının sürelerinin yetersiz olduğu görülmektedir.

3.3 EBA'da yer alan Türkçe dersi videolarının izlenme sayılarına göre dağılımı nasıldır?

Tablo 3. Türkçe Dersi Videolarının İzlenme Sayılarına Göre Dağılımı

\begin{tabular}{lll}
\hline İzlenme Say1S1 & $f$ & $\%$ \\
\hline $1-500$ & 24 & 19,2 \\
$501-2000$ & 74 & 59,2 \\
$2001-5000$ & 17 & 13,6 \\
$5001-10000$ & 7 & 5,6 \\
$10001-15000$ & 3 & 2,4 \\
\hline
\end{tabular}


Tablo 3, EBA'daki Türkçe dersi videolarının kullanıcılar tarafından izlenme sayılarını sunmaktadır. Videolardan $24^{\prime}$ ü $(\% 19,2)$ bir ile beş yüz defa arasında; 74 '̈̈ $(\% 59,2)$ beş yüz bir ile iki bin defa arasında; 17 'si $(\% 13,6)$ iki bin bir ile beş bin defa arasında; 7 'si $(\% 5,6)$ beş bin bir ile on bin defa arasinda; 3 '̈u $(\% 2,4)$ ise on bin bir ile on beş bin defa arasında izlenmiştir. Ülke-

Tablo 4. Türkçe Dersi Videolarının Kazanım Dağılımı Bakımından Sınıf Düzeylerine Uygunluğu

\begin{tabular}{lcc}
\hline Kazanımların Sınıf Düzeylerine Uygunluğu & $f$ & $\%$ \\
\hline Uygun & 71 & 56,80 \\
Uygun Değil & 54 & 43,20 \\
\hline
\end{tabular}

Tablo 4, EBA'da bulunan Türkçe dersi videolarının ağda yer aldığı sınıf düzeyine uygunluğunu göstermektedir. Buna göre videolardan 71 'i $(\% 56,80)$ ilişkilendirildiği sınıf düzeyine uygun iken $54^{\prime}$ ü $(\% 43,20)$ ilişkilendirildiği sınıf düzeyine uygun değildir. Bu durum; Türkçe dersi videolarının sinıf seviyelerine göre gruplandırılmasında videolarda verilmesi amaçlanan kazanımların hangi sınıf düzeyinde yer aldığının dikkate alınmadığı sonucunu akla getirmektedir. Örneğin "birleşik zamanlı fiiller" ve "ek fiilin cümleye kattığı anlam" başlıklı ve konulu 7. sınıf Türkçe dersi videosunu ele alırsak birleşik zamanlı fiiller ve ek fiil konusu-

Tablo 5. Türkçe dersi videolarında ele alınan konuların ilişkili olduğu kazanım alanlarına göre dağılımı ve belirtilen kazanımlarla ilişkili olma durumu

\begin{tabular}{lcc}
\hline Öğrenme Alanları & $f$ & $\%$ \\
\hline Dinleme/İzleme & 9 & 7,2 \\
Okuma & 3 & 2,4 \\
Yazma & 28 & 22,4 \\
Konuşma & 5 & 4 \\
Dil Bilgisi & 29 & 23,2 \\
Dinleme/Okuma & 4 & 3,2 \\
Dinleme/Yazma & 4 & 3,2 \\
Dinleme/Dil Bilgisi & 1 & 0,8 \\
Okuma/Yazma & 12 & 9,6
\end{tabular}

na ait kazanımların 8. sınıf kazanımları olduğunu görmekteyiz. Oysa EBA'da bu konu 7. sinıf videoları arasında yer almaktadır. Videoların sınıf düzeylerine göre gruplanmasında ele alınan konulara dair kazanımların hangi sınıf düzeyinde verildiği dikkate alınmamıştır. Uygunluk ölçütü sunumda ele alınan konukonuların hangi kazanımlarla ilişkili olduğu ve bu kazanımların hangi sınıf düzeyinde verildiğidir.

3.5 EBA'da yer alan Türkçe dersi videolarında ele alınan konular Türkçe Öğretim Programında yer alan hangi kazanımlarla ilişkilidir? 
Okuma/Dil bilgisi

$\begin{array}{cc}1 & 0,8 \\ 5 & 4 \\ 1 & 0,8 \\ 19 & 15,2 \\ 1 & 0,8 \\ 2 & 1,6 \\ 3 & 2,4 \\ 2 & 1,6\end{array}$

Yazma/Dil Bilgisi

Konuşma/Yazma

Dinleme/Okuma/Yazma

15,2

Dinleme/Okuma/Dil Bilgisi

0,8

Dinleme/Okuma/Yazma/Dil Bilgisi

1,6

Konuşma/Okuma/Yazma

Dinleme/Okuma/Yazma/Konuşma/Dil Bilgisi

1,6

Tablo 5, EBA'daki Türkçe dersi videolarında yer verilen konuların ilişkili olduğu öğrenme alanlarını sunmaktadır. Buna göre videolardaki konulardan 9'u dinleme/izleme; 3'ü $(\% 2,4)$ okuma; 28'i (\%22,4) yazma; 5'i (\% 4) konuşma; $29^{\prime}$ u $(\%$ 23,2) dil bilgisi; 4'ü $(\% 3,2)$ dinlemeokuma; 4'ü $(\% 3,2)$ dinleme-yazma; $1^{\prime}$ i $(\% 0,8)$ dinleme-dilbilgisi; 12 'si (\% 9,6) okuma-yazma; 1'i (\%0,8) okuma- dil bilgisi; 5'i (\%4) yazma-dil bilgisi; 1'i (\%0,8) konuşma-yazma; 19'u (\%15,2) dinleme-okuma-yazma; 1 'i $(\% 0,8)$ dinlemeokuma- dil bilgisi; 2 'si $(\% 1,6)$ dinleme-okumayazma-dil bilgisi; 3'ü $(\% 2,4)$ konuşma-okumayazma; 2'si $(\% 1,6)$ ise dinleme-okuma-yazmakonuşma ve dil bilgisi öğrenme alanlarının tamamı ile ilişkilidir. Videolarda yer alan hedef kazanımlar kimi zaman tek öğrenme alanı ile ilgili iken kimi zaman ise aynı anda birden çok öğrenme alanı ile ilgili olabilmektedir. Bu durum Türkçe dersi kazanımlarının ve becerilerin iç içe geçmiş olması ile açıklanabilir. Ancak videolarda derslerin işleniş sürecinde konuların sadece dil bilgisi kazanımları ile ilişkilendirildiği diğer öğrenme alanlarının yok sayıldığı görülmektedir.

3.6 EBA'da yer alan videolarda ders işleme süreci aşamalarına yer verilmiş midir?

Yapılandırmacı yaklaşıma göre Türkçe öğretiminin öğrenme-öğretme süreci beş aşamada ele alınmaktadır. Bunlar: Hazırlık, anlama, metin aracilığ1 ile öğrenme, kendini ifade etme ve ölçme ve değerlendirme aşamalarıdır (Güneş, 2009: 18) Fakat $\mathrm{EBA}^{\prime}$ da bulunan ders videola- rında ders işlenişinde bu aşamalara yer verilmediği görülmektedir. Ders işleniş sürecinde öğrenciler selamlandıktan sonra derste işlenecek konunun adı söylenmiş ve bu konu sunuş yoluyla öğretim yöntemi kullanılarak anlatılmiştır.

\subsection{EBA'da yer alan videolarda hangi öğretim} stratejileri kullanılmıştır?

EBA'da yer alan Türkçe dersi videolarında öğrenme-öğretme stratejilerinden sadece sunuş yoluyla öğretim yönteminden yararlanılmış, diğer öğrenme-öğretme stratejilerinden yararlanılmamıştır. Bu öğretim yönteminde öğrenci pasif durumdadır. Öğrencinin pasif hâlde bulunduğu öğretimin verimli olması mümkün değildir (Özbay, 2008: 130). Ders videolarındaki işleniş yönteminin tek düzeliği yapılandırmacı eğitim anlayışına da ters düşmektedir. Yapılandırmacı öğretimde öğrenci kendi kavramlarını oluşturur. Problemlere ilişkin kendi çözüm yollarını geliştir. Konular üzerinde kendi kontrolünü sağlar (Özden, 2003: 68). Oysa EBA ders videoları öğretim yaklaşımı bakımından öğrencinin bu kontrolü sağlamasını sağlayıcı özellik göstermemektedir. Diğer taraftan EBA ders videoları Yıldız ve arkadaşlarının (2006: 57-61) ortaya koyduğu "ana dili öğretimine esas teşkil eden çağdaş ilkeler" den yaparak ve yaşayarak öğrenme, çocuklar arasındaki bireysel farklılıkları dikkate alma, alıştırma ve tekrar yapma ve eğitim öğretimi öğrenme ortamlarında gerçekleştirme ilkelerine uygun değildir. Türkçe öğretimin Ders videola- 
rı canlandırmalar, öğrencilerin aktif katılımını sağlayıcı etkinlikler içerecek tarzda interaktif hâle dönüştürülebilir.

\section{SONUÇ VE ÖNERILER}

FATİH Projesi 2010 yılından itibaren hayata geçirildi. Projenin önemli bir parçası olan EBA'yla "Eğitim-öğretim sürecinde bilişim teknolojisi donanımlarını kullanarak etkin materyaller kullanılması, sinıf seviyelerine uygun, güvenilir ve incelemeden geçmiş doğru e-içeriklerin bulunabileceği sosyal bir platform olması amaçlanmıştır. Öğretmen ve öğrenciler başta olmak üzere eğitimin bütün paydaşları için tasarlanan EBA; teknolojiyi bir amaç olarak değil bir araç olarak kullanmak amacıyla tasarlanan sosyal bir eğitim platform olarak tanıtılmış ve tanımlanmıştı" (MEB, 2015). EBA'daki e- içeriklerin önemli bir bölümünü ders videoları oluşturmaktadır. Bunlardan araştırmamızın konusunu oluşturan Türkçe ders videoları incelendiğinde;

1. EBA'da yer 125 (yüz yirmi beş) Türkçe dersi videosundan dokuzu $(\% 7,2) 5$. sinıf; dördü $(\% 3,2)$ 6. sinıf; otuz yedisi $(\% 29,6) 7$. sinıf; yetmiş beşi (\%60) ise 8. sınıflar için hazırlanmıştır. Türkçe dersi videolarının yarıdan çoğu 8. sınıflara yöneliktir. Ders videolarının sınıflara göre dağılımı eşit değildir. Ortaöğretime geçiş sınavlarının 8. sınıfta yapılıyor olması bu sınıf düzeyindeki içeriklerin sayısının fazlalığını açıklayabilir.

2. Videolarda amaçlanan kazanımlar ve ders süreçleri dikkate alındığında Türkçe dersi videolarının sürelerinin yetersiz olduğu sonucuna varılmıştır. Türkçe dersi videolarının süresi bir dakika ile yirmi dört dakika arasında farklı zaman aralıklarındadır. Türkçe dersinin işleniş süreci ve kazanımlar düşünüldüğünde bu sürelerin Türkçe dersi için yetersiz olduğu anlaşılmaktadır. Videolar ders işleniş süreçlerine yer verilerek ve ilgili olduğu kazanımlara uygun olarak yeterli sürelerde olmalıdır.
3. Ülkemizde ortaokulların 5,,6.,7. ve 8. sınıflarında öğrenim gören öğrenci sayısı düşünüldügünde videoların izlenme oranlarının son derece düşük kaldığı söylenebilir. Videolarının izlenme sayılarına bakıldığında en az izlenen video yirmi beş, en çok izlenen video ise on bin dokuz yüz sekiz defa izlenmiştir. Videolarla ilgili kişi sayısı (öğrenci ve öğretmenler) dikkate alındığında söz konusu izlenme sayılarının az olduğu söylenebilir. Ders videoları amaçlandığı gibi etkin birer öğretim materyali hâline getirilmeli, böylece bu materyallerden yararlanan kişi sayısı artırılmalıdır.

4. Türkçe dersi videolarının önemli bir bölümünün (\%43.20) EBA'da yer verildiği sınıf düzeyine uygun olmadığı görülmektedir. MEB Türkçe Programındaki kazanım dağ1lımı ders videolarına doğru yansımamıştır. Örneğin 8. sınıfta işlenmesi gereken kazanım 7. sınıfta işlenmiştir. Konu başlıklarında da benzer durumlar söz konusudur. Türkçe dersi videoları, ilişkili olduğu kazanımlar ve bu kazanımların verildiği sınıf düzeyleri bakımından incelenmesi ve konu dağılımı bakımından yeniden düzenlenmesi uygun olacaktır.

5. Türkçe dersinin kazanımları göz önüne alındığında dinleme/izleme, okuma, yazma ve konuşma becerilerinin esas olduğu, dil bilgisi becerilerinin ise bu öğrenme alanları ile birlikte ele alınması gerektiği ifade edilmektedir. Ancak Türkçe dersi videoları incelendiğinde videolardaki konuların her birinin sadece dil bilgisi kazanımları çerçevesinde ele alındığı belirlenmektedir. Bu durum ise dil bilgisi öğretimini dolayısıyla Türkçe dersi videolarını bir araç olmaktan öte amaç konumuna getirmektedir. Türkçe dersi öğretim ilkeleri rehberliğinde Türkçe dersi kazanımları bütüncül bir anlayışla ele alınmalıdır.

6. Videolarında ders işleniş süreçlerinden "Hazırlık, anlama, metin aracılığı ile öğrenme, kendini ifade etme ve ölçme ve değerlendirme" aşamalarına yer verilmediği 
belirlenmiştir. Türkçe ders videoları yapılandırmacı öğretim gereği farklı öğretim strateji yöntem ve teknikleri kullanılarak ve ders işleniş sürecindeki aşamalara yer verilerek düzenlenmesi ders videolarının verimliliğini arttırabilir.

7. Videolarının Türkçe öğretimi bakımından "etkin materyal" olma özelliğini taşımadı̆̆ görülmektedir. Videolarda bir öğretmenin sunuş yoluyla öğretim yaklaşımını kullanarak dersleri bilgi verici bir tutumla anlattığ görülmektedir. Derslerin işleniş sürecinde yapılandırmacı öğretim prensipleri uyarınca farklı öğretim yöntem ve tekniklerinden yararlanılmadığı görülmektedir. Dersin uzaktan yapılması bakımından bu normal karşılanabilir ancak etkin bir öğretim için farklı öğretim yöntem ve tekniklerinden yararlanılması faydalı olacaktır.

EBA'da yer alan bütün içerikler araştırmamızda olduğu gibi incelenmek suretiyle ilgililere yol gösterecek çalışmaların sayısı artırılabilir ve içerikler sahip olması gereken niteliklere uygun olarak hazırlanabilir.

\section{Kaynakça}

Akyol, H. (2007). Vygotsky, piaget ve yapılandırmacı okuma eğitimi. VI. Ulusal Sinıf Öğretmenliği Kongresi, 27-29 Nisan, Eskişehir.

Brooks, J. G., \& Brooks, M. G. (1999). In search of understanding: The case for constructivist classrooms. ASCD.

Devlet Planlama Teşkilatı (DPT). (2006). Bilgi toplumu stratejisi 2006-2010. Ankara: DPT.

Güneş, F. (2009). Türkçe öğretiminde günümüz gelişmeleri ve yapılandırmacı yaklaşım. Mustafa Kemal Üniversitesi Sosyal Bilimler Enstitüsü Dergisi, 11, 1-21.

Karadağ E. ve Korkmaz T.(2007). Kuramdan uygulamaya yapılandırmacı öğrenme yaklaşımı: 1-5. Sınıf Etkinlik Örnekleriyle. Ankara: Kök

Kavcar, C., Oğuzkan, F. ve Sever, S. (2004). Türkçe Öğretimi. Ankara: Engin

Kayısı, F. ve Aydın, H. (2014) Fatih projesi kapsamında tablet bilgisayar içeriklerinin değerlendirilmesi. e-Uluslararası Ĕ̆itim Araştırmaları Dergisi, 3, 72-85.

Miles, M. B. \& Huberman, A. M. (1994). Qualitative data analysis. Thousand Oaks. CA: Sage.

Millî Eğitim Bakanlı̆̆ı (MEB). (2015). Eğitimde FATïH Projesi web sayfası. erişim http://FATIH Hrojesi.meb.gov.tr/tr/index.php

Millı̂ Eğitim Bakanlığı (MEB). (2015). Eğitimde FATiH Projesi web sayfası. erişim http://fatihprojesi.meb.gov.tr/tr/icerikincele.php?id=6

Özbay, M. (2008). Türkçe özel öğretim yöntemleri I (2. Baskl). Ankara: Öncü

Özden, Y. (2003). Öğrenme ve öğretme (6. Baskı) Ankara: Pegem A

Özdemir, E.(1983). Anadili öğretimi. Türk Dili Aylık Dil ve Yazın Dergisi, 379-380,18-30.

Saban, A. (2009). Çoklu zekâ kuramı ile ilgili türkçe çalışmaların içerik analizi. Kuram ve Uygulamada Eğitim Bilimleri / Educational Sciences: Theory \& Practice 9 (2), 833-876.

Sever, S. (2004). Türkçe öğretimi ve tam öğrenme(4. Baskl). Ankara: Anı Yayıncılık,

Tarhan, B. (2010) Çocuk tiyatrolarında içerik analizi: ankara devlet tiyatrosu örneği. Yayımlanmamış yüksek lisans tezi, Ankara Üniversitesi Ĕgitim Bilimleri Enstitüsü, Ankara.

Yıldırım, A. Şimşek, H.(2008). Sosyal bilimlerde nitel araştırma yöntemleri (7. Baskı). Ankara: Seçkin Yayıncllik. 
Yıldız, C. Okur, A. Arı, G. Yılmaz Y. (2006). Yeni öğretim programına göre kuramdan uygulamaya türkçe ögretimi. Ankara: Pegem A

Yurt, G. ve Arslan, M. (2014) 7. sınıf türkçe ders kitaplarının şekil-içerik-metin yönünden incelenmesi. Zambak ve pasifik yayınları örneği, SDÜ Fen Edebiyat Fakültesi Sosyal Bilimler Dergisi Journal of Social Sciences, 31, 317-327. 


\section{Extended Summary}

\section{Introduction}

There has been a very rapid development in the field of technology in our country and around the world. Especially computer technology has been used every moment and every fields of daily life. Keeping up with this rapid development in technology and utilizing its facilities within education become a must for the era we live. In this point of view, "Movement of Enhancing Opportunities and Improving Technology"(Fatıh) project has been developed with a consensus between Ministry of National Education and Ministry of Transport, Maritime Affairs and Communications in our country since 22.10.2010.

One of the most important extents of this project is Educational Informatics Network which is the second main component of FATIH Project abbreviated as "EBA". This is a social education platform designed to use virtual technology environment as a utility not as an aim. Lesson Videos are the most important parts in e-contents on EBA.

\section{The Purpose of the Research}

The purpose of the study is to examine the Turkish course video contents systematically in terms of different variables such as learning fields, its pace, the features of their interactions and learning strategies. So it has been intended to contribute in providing those electronic contents', used in Turkish courses, appropriate usage by clarifying the features for Turkish teaching.

Relevant with this aim in this study, the following questions are tried to be answered:

1. How is the distribution of the Turkish course videos exist in Educational Informatics Network in accordance with the levels of classes?

2. How long do the Turkish course videos exist in Educational Informatics Network process take?

3. What is the distribution number of watching the Turkish course videos exist in Educational Informatics Network?

4. Are the Turkish course videos exist in Educational Informatics Network appropriate for the levels of the applied classes in accordance with the acquisition distribution?

5. Which themes dealt with the Turkish course videos exist Educational Informatics Network are related with Turkish Education Programme acquisitions?

6. What learning strategies are used within the Turkish course videos exist in Educational Informatics Network?

7. Are the lesson application processes allowed to be used in the Turkish course videos exist in Educational Informatics Network?

\section{Method}

This is a descriptive research aims to investigate the Turkish course videos on Educational Informatics Network (EBA) systematically in terms of different variables.

In this study, data analyzing method has been used among the qualitative searching methods.

\section{Gathering data and analyzing}

The Turkish course videos analyzed in the current study are restricted with the Turkish course videos which were attained in 16 April 2015 by 5(n=10), 6(n=4), 7(n=37) and $8^{\text {th }}(n=76)$ grade students on http://www.eba.gov.tr/video/ortaokul-6-sinif-turkce, http://www.eba.gov.tr/video/ortaokul-7-sinifturkce, http://www.eba.gov.tr/video/ortaokul-8-sinif-turkce websites. 
All of the Turkish course video were watched by $5,6,7$ and $8^{\text {th }}$ grades but as one of the $8^{\text {th }}$ grade videos called "the Techniques of Studying Turkish Course" and one of the $5^{\text {th }}$ grade videos called "My Teacher" don't convey any presentation criteria, they weren't included into the study. So all data were collected form 125 Turkish course videos.

The current data were analyzed descriptively. Those data analyzed descriptive were summarized and commented according to the predetermined themes.

Firstly a framework is formed for the examined videos in order to analyze them. As a result of the examinations, seven questions were determined. Those prepared questions were presented to the experts who are competent in Turkish Education. The questions were reviewed according to the considerations of the experts and resent back to them. The feedbacks show that the experts are in an agreement.

125 course videos were carefully watched for several times and examined according to the predetermined seven questions/themes and subcategories of these themes. For example what is the distribution of teaching strategies used in Turkish course videos? Four different subthemes "expository teaching", "discovery teaching", "investigating and analyzing teaching", "full teaching method" were determined. Then 125 videos were watched again and given a code for each of the "subtheme".

The coding in the study was applied for two times in fifteen days. The two coding results were compared, calculated with reliability formulation (reliability=consensus+ dissensus x100) (Miles and Huberman, 1994) and the coherence between the two codes was found out as \%100.

SPSS package programme was used in order to analyze the encoded data. At first, all data and subdata were transferred into SPSS package programme. Afterwards it was controlled if the related theme or subtheme was exist in the videos (in a way as "exist" or "not exist") and how many times the themes were repeated were calculated as frequency(f) and percentage (\%). According to the achieved data, only the tables that provide data for only one theme were prepared. Instead of that all the findings were commented in paragraphs.

\section{Result}

It was evaluated that a considerable part of the Turkish course videos (\%43.20) were not appropriate for the grades presented in Educational Informatics Network.

None of the Turkish course videos have "active material" features for teaching Turkish.

When the acquisition of Turkish course is considered, listening, reading, writing and speaking abilities are the fundamental skills and language skills should be handled with those four skills. But when Turkish course videos are examined, it has been determined that each of the subjects in the videos are presented only within the language acquisition framework. This situation makes grammar teaching that also means Turkish course videos, not a tool but an aim.

Turkish course videos' durations are at different time intervals changes between one minute and twenty-four minutes. When the time limitation of a Turkish lesson and the acquisitions are considered, it is understood that those time spans are not enough for Turkish lessons.

When the Turkish course videos' watching number is examined, it is understood that the least watched video was seen for twenty-five times and the most watched video was seen for ten thousand nine hundred and eight times. When the people (students and teachers) who concerned with the videos are taken into consideration, it can be said that the numer of watching is low. 